\title{
The Janus-like role of neuraminidase isoenzymes in inflammation
}

\author{
Md. Amran Howlader ${ }^{1 \ddagger}$, Ekaterina P. Demina ${ }^{2 \ddagger}$, Suzanne Samarani ${ }^{2,4}$, Tianlin Guo ${ }^{1}$, Ali Ahmad ${ }^{2,4}$, \\ Alexey V. Pshezhetsky*2,3, Christopher W. Cairo*1
}

Affiliations:

${ }^{1}$ Department of Chemistry, University of Alberta, Edmonton, Alberta, T6G 2G2, Canada;

${ }^{2}$ Sainte-Justine Hospital Research Center, Division of Medical Genetics, University of Montreal, Montreal, Quebec, H3T 1C5, Canada;

${ }^{3}$ Department of Anatomy and Cell Biology, McGill University, Montreal, Quebec, H3A0C7, Canada

${ }^{4}$ Department of Microbiology, Infectious Diseases \& Immunology, Sainte-Justine Hospital Research Center, University of Montreal, Montreal, Quebec, H3T 1C5, Canada

${ }^{\ddagger}$ Contributed equally

*Correspondence:

Alexey V. Pshezhetsky

CHU Ste-Justine, Centre de recherche,

3175 Côte-Sainte-Catherine

H3T 1C5 Montréal

Québec, Canada

alexei.pchejetski@umontreal.ca

Christopher W. Cairo

CCIS 4-082, Department of Chemistry

University of Alberta

Edmonton, Alberta, T6G 2G2

Canada

ccairo@ualberta.ca

Running title: Human neuraminidases alter leukocyte infiltration 


\section{Abstract}

The processes of activation, extravasation, and migration of immune cells to a site are early and essential steps in the induction of an acute inflammatory response. These events are part of the inflammatory cascade which involves multiple regulatory steps. Using a murine air-pouch model of inflammation with LPS as an inflammation inducer we demonstrate that isoenzymes of the neuraminidase family (NEU1, 3, and 4) play essential roles in this process acting as positive or negative regulators of leukocyte infiltration. Genetically knocked-out (KO) mice for different NEU genes (Neul KO, Neu3 KO, Neu4 KO, and Neu3/4 double KO mice) were induced with LPS, leukocytes at the site of inflammation were counted, and the inflamed tissue was analyzed using immunohistochemistry. Our data show that leukocyte recruitment was decreased in NEU1 and NEU3-deficient mice, while it was increased in NEU4-deficient animals. Consistent with these results, systemic levels of proinflammatory cytokines and those in pouch exudate were reduced in Neul and increased in Neu4 KO mice. We found that pharmacological inhibitors specific for NEU1, NEU3, and NEU4 isoforms also affected leukocyte recruitment. We conclude that NEU isoenzymes have distinct - and even opposing - effects on leukocyte recruitment, and therefore warrant further investigation to determine their mechanisms and importance as regulators of the inflammatory cascade.

\section{Keywords}

neuraminidase, sialidase, sialic acid, inflammation, leukocyte

\section{Abbreviations}

BW, body weight; BMDM, bone marrow-derived macrophage; DKO, double knock out; IN1, inhibitor of NEU1 (CG14600); IN3, inhibitor of NEU3 (CG22600); IN4, inhibitor of NEU4 (CY16600); KO, knock out; LPS, lipopolysaccharide; MO, monocytes; MФ, macrophages; NE, neutrophil; NEU1, neuraminidase 1; NEU3, neuraminidase 3; NEU4, neuraminidase 4; NK, natural killer cells; WT, wild type 


\section{Introduction}

The induction of the inflammatory cascade by exogenous or endogenous stimuli culminates in acute inflammation: a host protective response that tends to neutralize the stimulus and maintains tissue homeostasis and integrity. However, when acute inflammation becomes uncontrolled and long-lasting, it contributes to the pathogenesis of chronic inflammatory diseases such as sepsis, diabetes, atherosclerosis, and cardiovascular disease. The cascade begins with activation and trafficking of leukocytes to the site of inflammation.(Ley et al, 2007) This process provides a rapid response to an infection by regulating permeability of the vascular compartment, activation of endothelial cells, tethering and adhesion of leukocytes to the vascular endothelium, and subsequent extravasation to the site of inflammation as well as activation of macrophages, platelets, complement, and clotting factors. Acute inflammation can be triggered by recognition of pathogen-associated molecular patterns (PAMPs), such as the lipopolysaccharide (LPS) of gram negative bacteria, by one or more pattern recognition receptors (PRR) of the host cells (e.g. Toll-like receptors, TLRs).(Rossol et al, 2011) For example, LPS is recognized by TLR-4 leading to initiation of the inflammatory cascade and leukocyte recruitment.(Miyake, 2004) The glycosylation state and activity of cellular receptors, including TLR-4, is known to be regulated by endogenous neuraminidase enzymes (NEU, or sialidases).(Amith et al, 2010; Feng et al, 2012; Pshezhetsky \& Hinek, 2011) Notably, there are four NEU isoenzymes, each with distinct tissue expression, subcellular localization, and roles in inflammation and pathogenesis.(Miyagi \& Yamaguchi, 2012) These enzymes remove sialic acid from the termini of glycoproteins, glycolipids, and oligosaccharides in a substrate- and linkagespecific manner. Increased endogenous neuraminidase activity, accompanied by leukocyte activation, is known to play a role in the infiltration of leukocytes to the site of inflammation; however, the precise role of individual NEU isoenzymes in leukocyte recruitment has not been investigated in a systematic fashion.(Feng et al, 2011; Gadhoum \& Sackstein, 2008)

$\mathrm{N}$-Acetyl-neuraminic acid (Neu5Ac, or sialic acid) residues are known to be important in multiple steps of the inflammatory cascade. Selectins, expressed by immune cells as well as by vascular endothelial cells (VEC), mediate leukocyte capture and rolling and require minimal tetrasaccharide epitopes containing Neu5Ac residues (sialyl-Lewis ${ }^{\mathrm{X}}$; $\mathrm{sLe}^{\mathrm{X}}$ or CD15s) for binding with their ligands (e.g. PSGL-1, CD44).(Zen et al, 2007) Endogenous NEU are able to desialylate these epitopes, thus disrupting selectin-ligand interactions.(Gadhoum \& Sackstein, 2008) The firm adhesion step of the cascade is mediated by activated leukocyte $\beta 2$ integrins, LFA-1 (CD11a/CD18) and MAC-1 (CD11b/CD18), which bind immunoglobulin-like adhesion molecules (ICAM-1 and ICAM-2) expressed by activated VEC. Activation epitopes of $\beta 2$ integrins were reported to be unmasked by endogenous NEU activity,(Feng et al., 2011; Quinn et al, 2001) and NEU3 has been shown to alter LFA-1/ICAM1 interactions.(Howlader et al, 2019) NEU enzymes can increase adhesion of polymorphonuclear leukocytes $(\mathrm{PMN})$ to endothelium and also increase their migration through the endothelium to the site of 
inflammation.(Cross et al, 2003; Sakarya et al, 2004) NEU enzymes may unmask epitopes in $\beta 1$ integrins VLA4 (CD49d/CD29) and VLA5 (CD49e/CD29), which are expressed on activated leukocytes and bind with VCAM1 and fibronectin (FN).(Feng et al., 2011; Quinn et al., 2001) Activated PBMCs have been shown to increase production of inflammatory cytokines such as TNF- $\alpha$ and IFN- $\gamma$ through the action of NEU1 or NEU3.(Nan et $a l, 2007$ ) The effect of cytokine production (e.g. IL-6, IL-12p40, and TNF- $\alpha$ ) in dendritic cells has been reported to be regulated by NEU1 and NEU3 activity.(Stamatos et al, 2010) NEU1 has been shown to induce phagocytosis in macrophages by activation of Fc- $\gamma$ receptors.(Seyrantepe et al, 2010) Together, these findings suggest that endogenous NEU activity is involved at multiple points along the inflammatory cascade.

To test the hypothesis that individual NEU isoenzymes have different effects on inflammation and to address specific roles of these enzymes in recruitment of leukocytes to the site of inflammation, we used a murine sixday air pouch model of LPS-induced acute inflammation(Sin et al, 1986) in Neu1, Neu3, and Neu4 KO and WT mice (in an identical C57B16 genetic background). In previous studies we demonstrated that Neu3 and Neu4 enzymes have similar substrate specificity and can complement each other;(Smutova et al, 2014) therefore, we also tested Neu3/4 double KO (DKO) animals deficient in both enzymes.(Pan et al, 2017) We observed that NEU isoenzymes drastically modulated the inflammatory response to LPS, with NEU1 and NEU3 isoenzymes acting as positive regulators and NEU4 acting as a negative regulator of the response. These results reveal that NEU isoenzymes have important and distinct roles in the regulation of immune cell migration to the site of inflammation as well as consequent inflammation. Moreover, our findings suggest that NEU isoenzymes play roles in immune response and may be targets to modulate pathogenic inflammation in human disease.

\section{Materials and Methods}

\subsection{Animal models}

C57BL6 mice (aged 3-4 months) were used as wild type control. Neu1 KO, Neu3 KO, Neu4 KO, and Neu3/4 DKO mice were as reported previously.(Pan et al., 2017) Mice were housed in an enriched environment with continuous access to food and water, under constant temperature and humidity, on a $12 \mathrm{~h}$ light/dark cycle. The experiments involving animals were approved by the Animal Care and Use Committee of the CHU Ste-Justine Research Center (protocol \#710). WT and Neul KO group contained both male and female mice, while other groups contained male mice only.

\subsection{Sources of reagents and antibodies}

Compounds IN1(CG14600), IN3(CG22600), and IN4(CY16600) were prepared as previously reported.(Albohy et al, 2013; Guo et al, 2018a; Guo et al, 2018b; Zhang et al, 2013) Stock solutions for all compounds were made using saline. An LPS isolated from E. coli O55:B5 that does not contain sialic acid was purchased from Sigma Aldrich (cat\# L2880).(Lindberg et al, 1981) Anti-mouse/human CD11b FITC (Clone 
M1/70), anti-mouse CD45 Alexa Fluor 700 (Clone 30-F11), anti-mouse/human CD45R/B220 PerCP (Clone RA3-6B2), anti-mouse 49b PE (Clone DX5), anti-mouse F4/80 APC (Clone BM8), anti-mouse Ly-6G PE/Cyanine 7 (Clone 1A8), anti-mouse Ly-6C Brilliant violet 421 (Clone HK1.4), and anti-mouse CD115 APC/Cyanine 7 (Clone AFS98) were purchased from Biolegends, USA.

\subsection{Air pouch model of acute inflammation}

The air pouch inflammation model was previously described and used here with slight modifications.(Cronstein et al, 1993; Terkeltaub et al, 1998; Tessier et al, 1997) Briefly, mice (6-8 weeks, male or female) were randomly separated into control and experimental groups. Hair was removed at the dorsal area $(5 \times 2 \mathrm{~cm})$ two days prior to commencing the experiment, vaseline was applied on the nude area to alleviate discomfort. Animals were monitored for abnormal behavior and skin injuries daily. On days 3 and 6, mice were anesthetized under isoflurane and $3 \mathrm{~mL}$ of sterilized air (passed through a $0.2 \mu \mathrm{m}$ filter) was injected subcutaneously into the back of the mice using a 26-gauge needle. For treated mice, an intraperitoneal injection of an inhibitor on days 6, 7, and $8(200 \mu \mathrm{L}$ of saline containing inhibitors at $1 \mathrm{mg} / \mathrm{kg}$ ). Saline was injected for control groups and mice that were not subjected to inhibitors. On day $8,1 \mathrm{~mL}$ of sterile PBS or sterile PBS with LPS $(1 \mu \mathrm{g} / \mathrm{mL})$ was injected into the air pouches. At $9 \mathrm{~h}$ post-injection, mice were sacrificed using phenobarbital overdose $(150 \mathrm{mg} / \mathrm{kg} \mathrm{BW})$. Then air pouches were washed with HBSS containing $10 \mathrm{mM}$ EDTA $(1 \mathrm{~mL}, 2$ X $2 \mathrm{~mL})$. The exudates were collected and centrifuged at $100 \mathrm{x}$ g for $10 \mathrm{~min}$ at room temperature. The supernatants were collected and frozen for later analysis. Cells were re-suspended in $1 \mathrm{~mL}$ of HBSS-EDTA and counted by haemocytometer or used in flow cytometry analysis.

\subsection{Flow cytometry analysis of immune cells}

Subpopulations of cells isolated from the air pouch exudate were analyzed by flow cytometry as previously described.(Nguyen et al, 2013) Dead cells were stained with Aqua blue (Thermo Fisher Scientific) and Fc Receptors (FcR) were blocked using mouse IgG. After washing with PBS (containing 2\% FBS), cells were incubated on ice for 30 min with fluorophore-conjugated antibodies as a mixture: CD49b PE, CD45 AF700, CD115 APC/CY7, Ly-6C BV421, Ly-6G PE/CY7, F4/80 APC, B220 PerCP, CD11b FITC, CD3 FITC, and CD11c APC. Briefly, cells were washed twice with PBS, resuspended in 2\% paraformaldehyde, and analyzed by Flow cytometry using BD LSRII Fortessa. Single fluorochromes were used for compensation (elimination of spectral overlap), and for setting of gates using a minus one method. Data were analyzed by Diva and FlowJo. Dead cells and doublets were eliminated from the analyses.

\subsection{Immunohistochemistry protocol and cell counts}

Immunohistochemistry (IHC) slides of Tissue Tek OCT pouch tissue were prepared by making $4 \mu \mathrm{m}$ thick slices and then staining them with hematoxylin and eosin (H\&E) stain. The slides were then imaged using a ZEISS Axio Scan Z1. Regions of the IHC slides were identified as three major regions: epidermis layer, dermis, 
and underlying muscle layer. The H\&E stain revealed leukocytes present in each region. The number of leukocytes were counted with ImageJ using at least three randomly chosen fields of the same region. Skin sections of at least three mice were investigated from each group.

\subsection{Cytokine analysis using ProcartaPlex immunoassays}

Levels of cytokines in mouse plasma and exudates were investigated using ProcartaPlex immunoassays (Perkin Elmer, USA) with a custom panel of 21 cytokines according to the manufacturer's protocol. Briefly, plasma and exudate samples were diluted in sample diluent and incubated with capture antibody-coupled magnetic beads on a shaker at $4{ }^{\circ} \mathrm{C}$ overnight. After removal of samples by centrifugation and three washes, biotinylated secondary antibody was added for incubation on shaker in the dark at room temperature for $30 \mathrm{~min}$. Each captured cytokine was detected by addition of streptavidin-phycoerythrin and fluorescence was measured using the Autoplex Analyser CS1000 system (Perkin Elmer, Waltham, MA).

\subsection{Macrophage preparation and chemotaxis trans-migration studies}

Monocytes (MO) were isolated from the bone marrow of mice and differentiated in vitro into macrophages (MФ) by incubating bone marrow cells in complete DMEM (cDMEM, DMEM supplemented with 10\% heatinactivated FBS, 10\% conditioned media supernatant from L-929 fibroblast cell cultures, 1\% penicillinstreptomycin, 0.01M HEPES buffer, $1 \mathrm{mM}$ sodium pyruvate). Macrophages were cultured for 7 days in a T75 flask with $80 \%$ confluency. Cells were then used for a transmigration assay adopted from a previous study.(Senger et al, 2002) Briefly, an 8- $\mu \mathrm{m}$-pore size transwell migration plate (Costar, Fischer Sci, USA) was used after the transwell membrane was coated with $50 \mu \mathrm{g} / \mathrm{mL}$ fibronectin (FN) in PBS for $1 \mathrm{~h}$ and blocked with bovine serum albumin (BSA) for $30 \mathrm{~min}$. The bottom chamber of the plate contained PBS with 20 ng/well monocyte chemoattractant protein-1 (MCP-1, Thermofisher Scientific, USA). Macrophages (5x10 4 cells in PBS) isolated from the genotypic mice were carefully placed on the top chamber and incubated for $5 \mathrm{~h}$ at $37{ }^{\circ} \mathrm{C}$ with $5 \% \mathrm{CO}_{2}$. Subsequently, the bottom of the upper chamber was carefully wiped using a Q-tip and the transwell membrane was stained. Cells that had infiltrated the membrane were then imaged using Zeiss COLIBRI fast LED imaging and optical sectioning microscope using 10X lens under bright field. The images were analyzed using Zen black software (Zeiss).

\section{Results}

\subsection{Inflammatory response to LPS reveals involvement of neuraminidase enzymes in the recruitment of leukocytes}

We used a murine air-pouch model to investigate the effect of individual neuraminidase enzymes on LPSinduced inflammation.(Sin et al., 1986) An air pouch was created by subcutaneous injection of sterile air into the lower dorsal region of WT and Neul KO, Neu3 KO, Neu4 KO, and Neu3/4 DKO mice (see Materials \& Methods). 
The pouch was injected with either $1 \mu \mathrm{g}$ LPS in $1 \mathrm{~mL}$ of saline, to simulate a bacterial infection, or $1 \mathrm{~mL}$ of saline, which served as a control for basal levels of inflammation. After an incubation period of $9 \mathrm{~h}$, the air pouch was washed with sterile saline to harvest cells, which were then counted by flow cytometry (Figure 1, Table 1). The differences in the pouch cell counts between WT and the Neu KO mice at basal level were non-significant (Figure 1B). In contrast, LPS treatment showed significant differences in the cell numbers between WT and Neu KO mice (Figure 1C). In the case of Neul KO animals, leukocyte counts were reduced to $\sim 25 \%\left(79 \pm 9 \times 10^{4}\right.$ cells/pouch $)$ of those in WT mice $\left(326 \pm 29 \times 10^{4}\right.$ cells/pouch). The Neu3 KO animals also showed a trend for reduction of leukocytes infiltrating the pouch in response to LPS as compared to the WT mice; however, the difference was not statistically different from control. The Neu4 KO $\left(1371 \pm 229 \times 10^{4}\right.$ cells/pouch) and Neu3/4 DKO (992 \pm $141 \times 10^{4}$ cells/pouch) animals demonstrated significant increases (3-4 fold) in cell numbers as compared with the WT mice upon LPS treatment. These results suggested that LPS-stimulated leukocyte infiltration into the pouch was positively regulated by NEU1, and negatively regulated by NEU4.

\subsection{Leukocyte subset response to LPS in neuraminidase deficient animal models}

To determine the influence of neuraminidases on leukocyte subsets found in the air pouch model, we stained cells from the exudate with cell type-specific antibodies and quantified them using flow cytometry. Cell counts were normalized to saline-treated WT control for the selected leukocyte subsets shown in Figure 2 (Figure SI1 and Table SI1 provide raw counts). We observed that the major populations found in the air pouch after LPS treatment were monocytes (MO), neutrophils (NE), natural killer cells (NK), and macrophages $(\mathrm{M} \Phi)$. T and B lymphocyte counts were low for both conditions, and no significant changes in their levels were detected for any of NEU-deficient animals as compared to WT mice (Table SI1). Other subsets analyzed revealed cell typespecific differences between NEU-deficient and WT mice. Specifically, Neul KO animals had increased basal $\mathrm{MO}$ and NE counts (saline treatment). In contrast, Neu4 KO animals had elevated counts of MO, NE, and NK cells after LPS treatment (3-9 fold increase as compared to WT), as well as elevated basal MO counts (5-fold increase as compared to WT). The Neu3 KO animals had elevated MO counts in saline controls. The Neu3/4 DKO animals showed moderate elevation of MO counts after LPS treatment. These results are generally consistent with NEU4 acting as a negative regulator of MO, NE, and NK cell infiltration upon LPS stimulation. 
A.

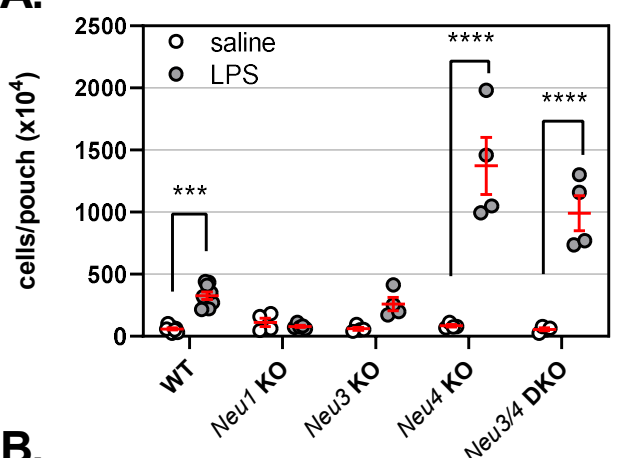

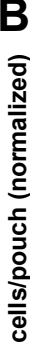
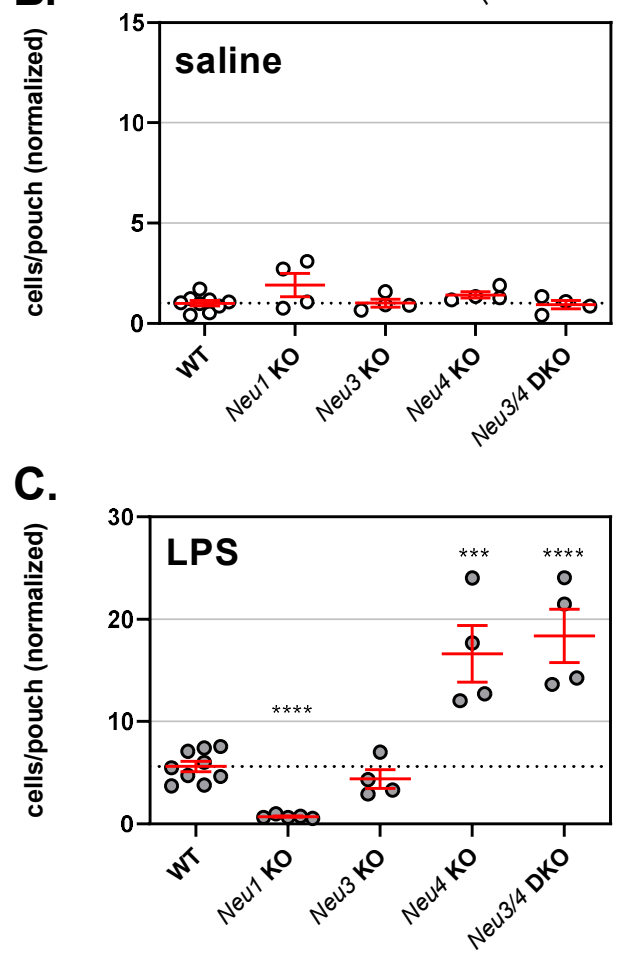

Figure 1. Leukocyte counts from the air pouch exudate. An air pouch was formed after injection of sterile air for each genotype. The pouch was then injected with saline or LPS and incubated for $9 \mathrm{~h}$. Mice were then sacrificed, the pouch exudate was collected, and cells were counted by flow cytometry. A. Cell counts are presented for the saline $(\mathrm{O})$ and LPS $(\bullet)$ treatments. B. Cell counts for the saline treatment in the Neu KO mice are compared with those of WT mice $\left(58 \times 10^{4}\right.$ cells/pouch; normalized to 1 , dashed line). C. Cell counts for the LPS treatment are compared with those of WT mice (normalized to WT saline treatment). Individual points are shown with mean \pm SEM. For panel A, comparisons were made using two-way ANOVA following Dunnet's multiple comparison test; for panel B \& C, comparisons were made using one-way ANOVA and Dunnet's t-test to compare groups to control. $(*, \mathrm{p} \leq 0.05 ; * *, \mathrm{p} \leq 0.01 ; * * *, \mathrm{p} \leq 0.005 ; * * * *, \mathrm{p} \leq 0.0001)$. 


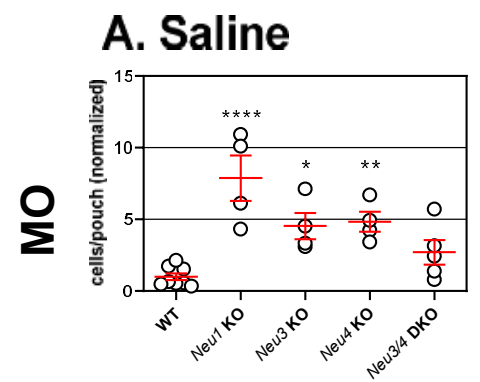

\section{B. LPS}
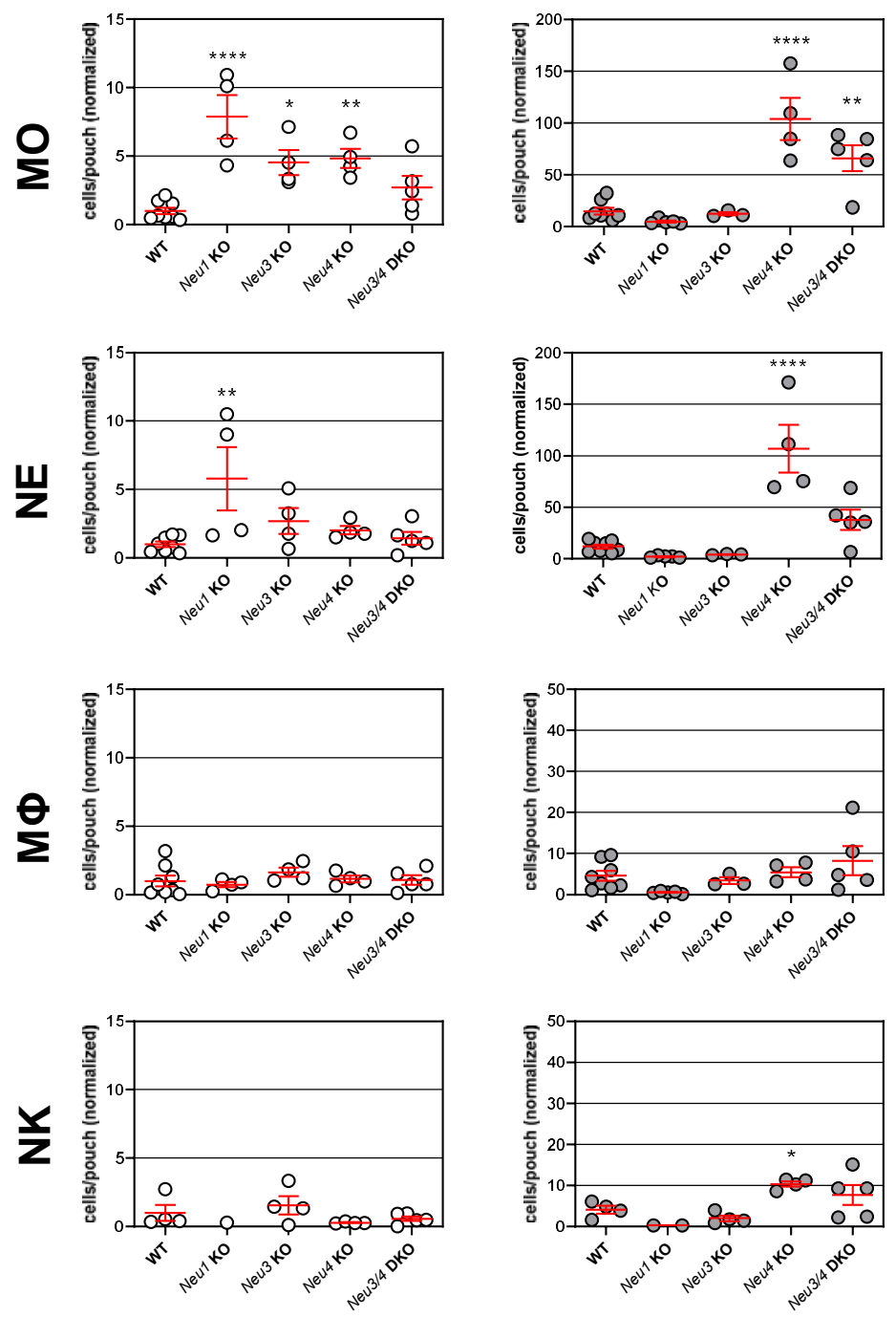

Figure 2. Changes in leukocyte populations in the air pouch model. Leukocytes collected from animals after saline $(\mathrm{O})$, or LPS $(\bullet)$ treatment were counted by flow cytometry. The cells were identified after staining with marker-specific fluorochrome-conjugated antibodies as monocyte (MO), neutrophil (NE), macrophage (M $\Phi)$, or natural killer (NK) cells. Animals used were WT, Neul KO, Neu3 KO, Neu4 KO and Neu3/4 DKO mice. The air pouch exudate was collected after $9 \mathrm{~h}$. The data are presented as cell counts (individual values and mean $\pm \mathrm{SEM}$ ) compared to the WT saline controls (monocyte, 7.4; neutrophil, 4.7; macrophage, 2.3; NK, $9.1 \times 10^{4}$ cells/pouch). Means were compared to those of control groups using one-way ANOVA followed by a Dunnet's t-test (*, p $\leq$ $0.05 ; * *, \mathrm{p} \leq 0.01 ; * * *, \mathrm{p} \leq 0.005 ; * * * *, \mathrm{p} \leq 0.0001)$. Raw cell counts are presented in Figure SI1. 


\subsection{Immunohistochemistry detects different levels of leukocyte infiltration in NEU-deficient animals.}

To add further support to our conclusions regarding leukocyte infiltration, tissue samples from the air pouch walls were analyzed for leukocyte infiltration (Figure 3, Table SI2, Figure SI2). Sections of the tissues were stained with $\mathrm{H} \& \mathrm{E}$ reagent and relative numbers of leukocytes in dermal and muscular layers were determined by microscopy. In the dermis layer of saline-treated Neul KO animals, the levels of leukocytes were increased as compared to those in WT animals, but no difference was observed in the muscle layer. In contrast, in LPS-treated Neul KO animals, leukocyte levels were significantly reduced in both dermis and muscle layers. In the muscle of LPS-treated Neu3 KO animals, we observed a reduction in leukocytes. Neu4 KO animals showed increased leukocyte counts in dermis and muscle layers with LPS treatment, and in muscle with saline treatment as compared with WT controls. This effect was attenuated in the Neu3/4 DKO animals: while elevated counts in dermis and muscle were observed for saline controls, LPS treatment resulted in leukocyte counts either similar (dermis) or reduced (muscle) as compared with those in WT controls. These observations are consistent with results of cytometry analyses of serum and pouch exudates (vide supra) and provide additional support to the hypothesis that NEU1 and NEU3 act as positive regulators of infiltration, while NEU4 acts as a negative regulator.

A.

B.

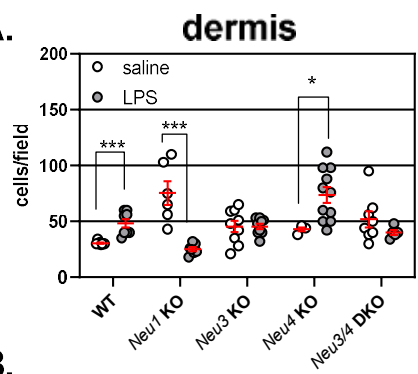

C.
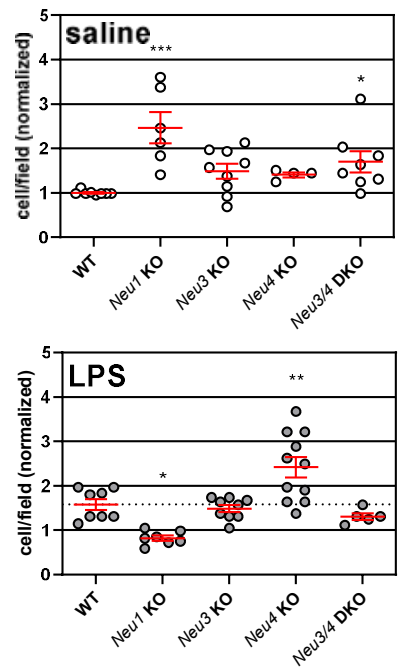

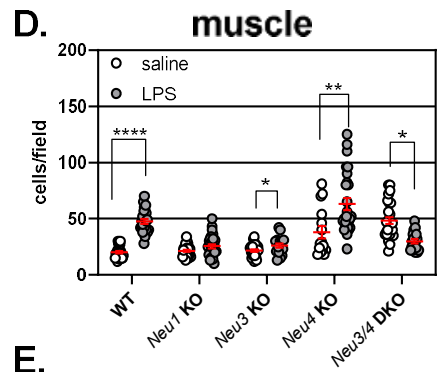

E.

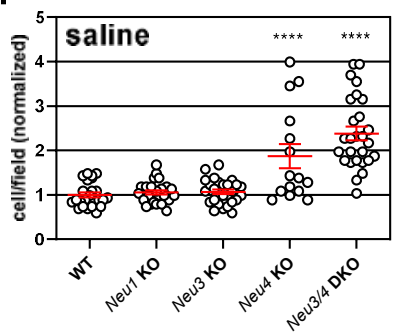

F.

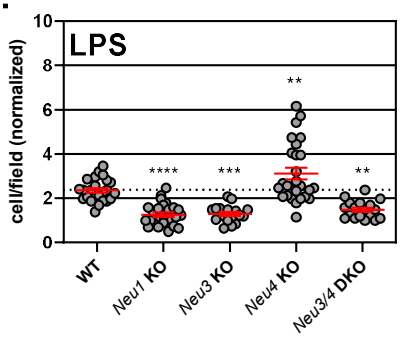

Figure 3. Levels of leukocytes in skin slices from the air pouch model. Tissue from the air pouch model was collected, sectioned, and stained (with H\&E reagent). Regions of tissue were identified as dermis or muscle. See Fig SI2 for representative images of each region in different mice groups. Random fields from each region were 
used to determine leukocyte counts after saline $(\mathrm{O})$ or LPS $(\bullet)$ treatment. Panels A. and D. show raw cell counts for each condition and tissue. Normalized cell counts after saline and LPS treatment are provided for dermis (B $\& \mathrm{C})$ and muscle $(\mathrm{E} \& \mathrm{~F})$ layers, respectively. The graphs show individual values and means $\pm \mathrm{SEM}$. Conditions were compared using a two-way ANOVA with Holm-Sidak's multiple comparison (A and D) or one-way ANOVA followed by Dunnet's multiple comparison $\left(\mathrm{B}, \mathrm{C}, \mathrm{E}\right.$, and F) ${ }^{*}, \mathrm{p} \leq 0.05 ; * *, \mathrm{p} \leq 0.01 ; * * *, \mathrm{p} \leq 0.005 ; * * * *, \mathrm{p} \leq$ $0.0001)$.

\subsection{Effect of neuraminidases on cytokine levels in circulation and exudates}

Based on the above findings, we concluded that NEU-deficient animals demonstrate altered regulation of leukocyte recruitment in the air-pouch model. One potential mechanism for these changes could involve the modulation of cytokine and chemokine production in the animals. To test this, air poach exudates and serum samples collected at sacrifice from WT, Neul KO and Neu4 KO mice were analyzed for a panel of 21 different cytokines and chemokines (Table 2, Table SI3 \& SI4).

As expected, levels of pro-inflammatory cytokines and chemokines were low in the exudates of control (saline treated) WT mice and were drastically increased in the exudates of LPS-treated animals. The LPS-treated Neu1 KO mice showed significantly attenuated levels of a range of inflammatory modulators such as G-CSF, IL-1 $\beta$, IL-6, IL-10, MIP1- $\alpha$, MIP-2, and TNF- $\alpha$ as compared with LPS-treated WT mice (Figure 4, Figure SI3). The Neul KO animals also showed increased levels of GM-CSF in exudate after LPS treatment, while saline-treated animals had basal activation of IL-10 and IL-33. The LPS-treated Neu4 KO animals had distinct changes to exudate cytokine levels. We observed attenuation of G-CSF, IFN- $\gamma$, and MCP-1 and activation of GM-CSF, IL$1 \beta$, IL-21, IL-33, MIP1- $\alpha$, MIP-1 $\beta$, and MIP-2 in the exudates from Neu4 KO animals.

We also examined plasma samples from these animals to observe systemic changes in cytokine levels. The LPS induction of 8 cytokines (G-CSF, RANTES, IL-6, IL-10, IFN- $\gamma$, MIP1- $\alpha$, MIP-1 $\beta$, and MIP-2) was significantly reduced in the plasma samples of Neul KO as compared with LPS-treated WT mice, similar to exudate samples. The Neul KO mice showed elevated levels of TNF- $\alpha$ in plasma. Cytokines significantly induced in saline-treated Neul KO animals included IL-1 $\alpha$, IL-1 $\beta$, IL-15, IL-25, and MIP-2 (Figure 5). The response of Neu4 KO animals to LPS was attenuated for 5 cytokines in plasma (G-CSF, RANTES, IL-10, MIP-1 $\alpha$, and MIP$1 \beta$ ). Basal activation of IP-10 was observed in Neu4 KO plasma samples. 
A.

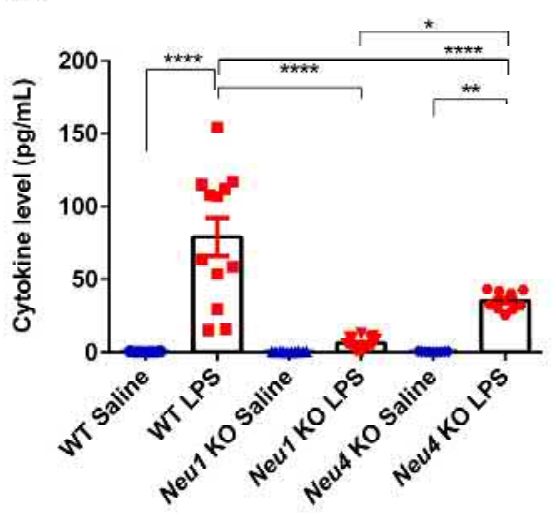

C.

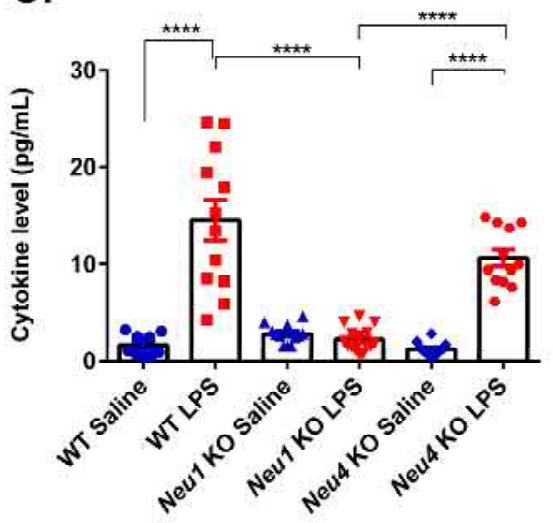

B. MIP-1 $\alpha$ exudate

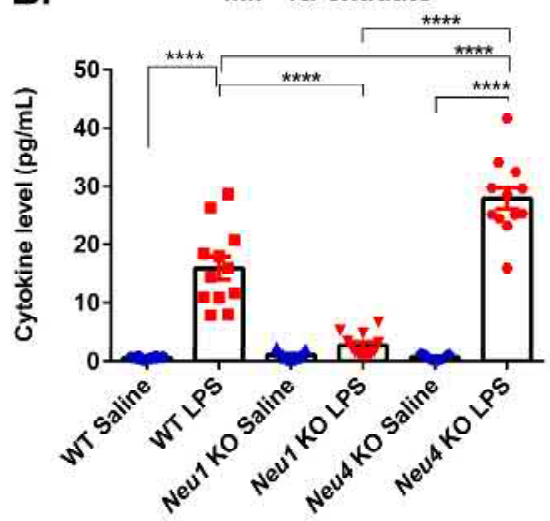

D.

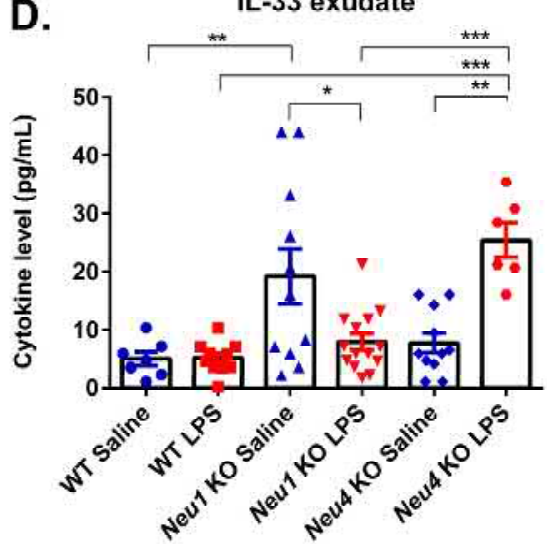

Figure 4. Cytokine levels in air poach exudates. Cytokines were analyzed using the Autoplex Analyser CS1000 system (Perkin Elmer, Waltham, MA) with a commercial ProcartaPlex Mouse Cytokine Panel Assay kit (Thermo Fisher Scientific Inc., Rockford, USA) in accordance with the manufacturer's instruction. (A) G-CSF, (B) MIP$1 \alpha$, (C) IL-10 and (D) IL-33 are shown as representatives, see Table 2 and Supporting information for other cytokines tested. Bars represent the mean values \pm standard error of the mean (SEM) in units of $\mathrm{pg} / \mathrm{mL}$. Samples were compared to controls using a one-way ANOVA multiple comparison and Tukey's test post-hoc analysis (*, $\mathrm{p}<0.05 ; * *, \mathrm{p}<0.01 ; * * *, \mathrm{p}<0.001 ; * * * *, \mathrm{p}<0.0001)$. 

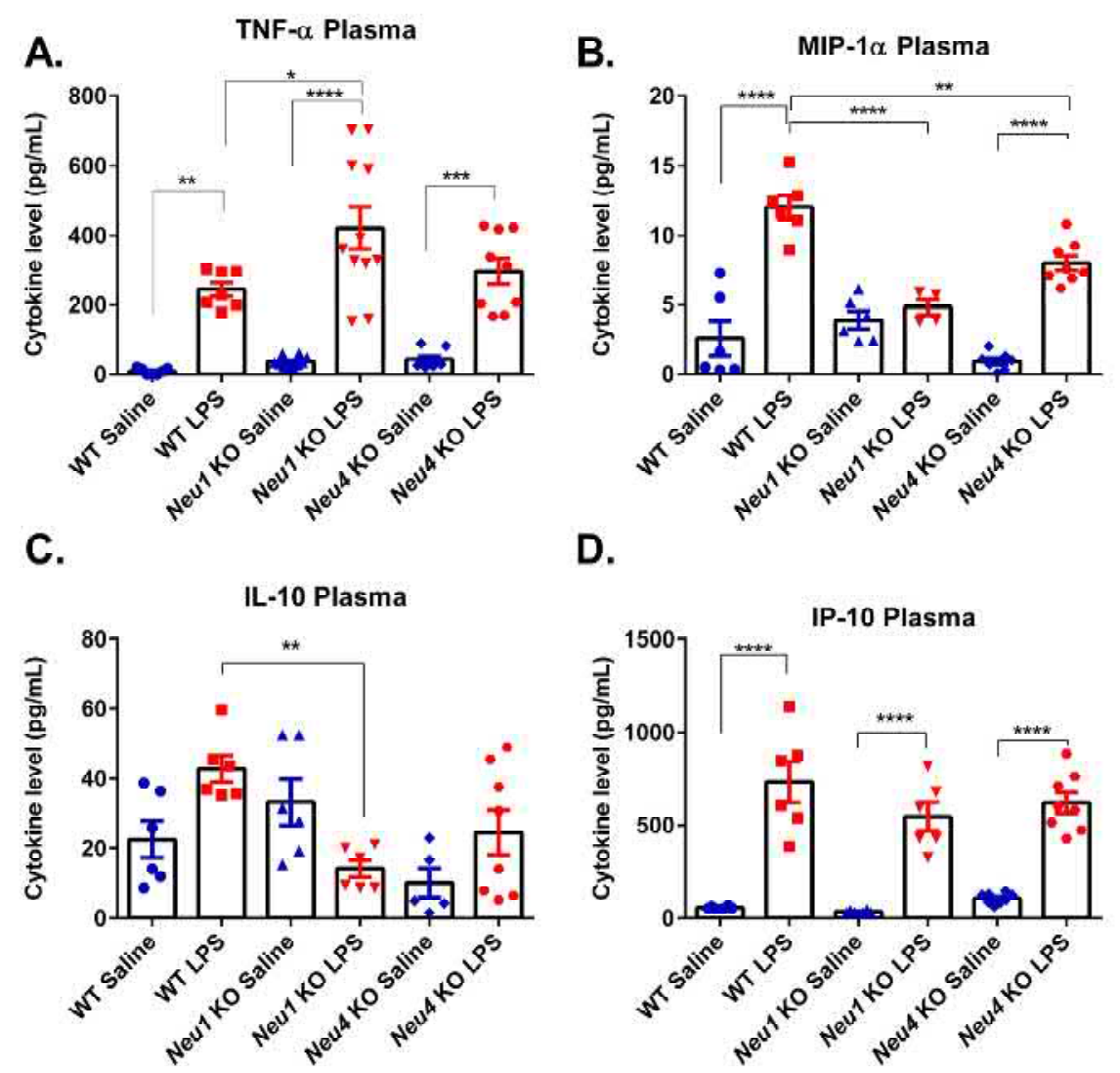

Figure 5. Cytokine levels in mouse plasma. Cytokines were analyzed using the Autoplex Analyser CS1000 system (Perkin Elmer, Waltham, MA) with a commercial ProcartaPlex Mouse Cytokine Panel Assay kit (Thermo Fisher Scientific Inc., Rockford, USA) in accordance with the manufacturer's instruction. (A) TNF- $\alpha$, (B) MIP$1 \alpha$, (C) IL-10 and (D) IP-10 are shown as representatives, see Table 2 and Supporting information for other cytokines tested. Bars represent the mean values \pm standard error of the mean (SEM) in units of pg/mL. Samples were compared to controls using a one-way ANOVA multiple comparison and Tukey's test post-hoc analysis (*, $\mathrm{p}<0.05 ; * *, \mathrm{p}<0.01 ; * * *, \mathrm{p}<0.001 ; * * * *, \mathrm{p}<0.0001)$

\subsection{Neuraminidase enzymes affect macrophage migration in vitro}

Our observations from the air pouch model of inflammation clearly indicated that NEU isoenzymes can have dramatic impacts on leukocyte recruitment to sites of inflammation. To gain further insight into a potential mechanism, we investigated the effect of NEU deficiency on the migration of bone-marrow derived macrophages (BMDM) from these animals. For the migration assay, cultured BMDM from the indicated genotype were seeded into the top chamber of a transwell culture plate where the membrane separating the upper and lower chambers had been coated with fibronectin (FN). To the lower chamber of the plate, a chemoattractant (CCL2/MCP-1) was added. Nine hours after addition of BMDM to the upper chamber, we counted numbers of the leukocytes that infiltrated the membrane by microscopy (Figure SI4), the results are summarized in Figure 6. The migration 
experiment revealed that macrophages from $\mathrm{Neul} \mathrm{KO}$ animals were not able to migrate into a FN matrix. In contrast, the macrophages from Neu3 $\mathrm{KO}$ animals demonstrated increased migration into the FN matrix. Macrophages from the Neu4 KO animals showed no differences from WT controls.

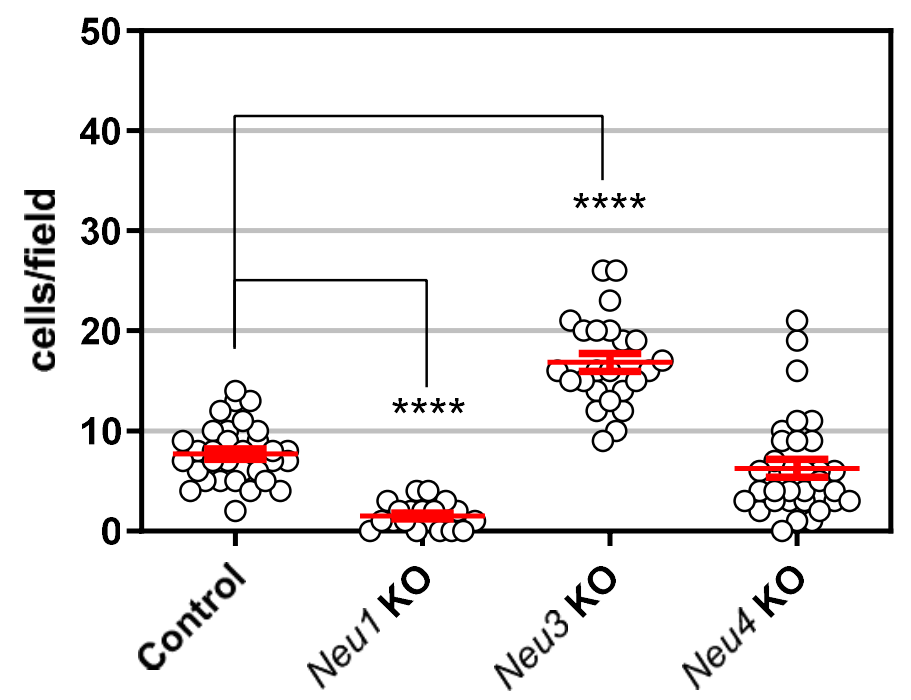

Figure 6. Migration of bone marrow-derived macrophages is affected by NEU expression. Macrophages were isolated and differentiated from bone marrow of WT, Neul KO, Neu3 KO, and Neu4 KO mice. Cells (2.5 $\mathrm{x} 10^{4}$ ) were placed in the upper chamber of the transmigration plate and the experiment was carried out for $5 \mathrm{~h}$ with MCP-1 as a chemoattractant in the lower chamber. The number of cells that infiltrated the FN-coated membrane was determined by counting of stained cells. Cell counts are plotted as mean $\pm \mathrm{SEM}$. Conditions were compared using a One-way ANOVA following Dunnett's t-test for comparison between groups. $(*, p \leq 0.05 ; * *$, $\mathrm{p} \leq 0.01 ; * * *, \mathrm{p} \leq 0.005 ; * * * *, \mathrm{p} \leq 0.0001)$.

\subsection{Effect of pharmacological inhibition of NEU on leukocyte subsets}

Based on our findings, we considered that inhibitors of NEU isoenzymes should be able to recapitulate some of the effects of gene targeting on cell infiltration in the air-pouch inflammation model. We used previously reported inhibitors selective for NEU1, NEU3, and NEU4 (Table 3); compounds were dosed at $1 \mathrm{mg} / \mathrm{kg}$ body weight and delivered by IP injection 48 h, 24 h, and 9 h before sacrifice (Table 1, Figure 7).(Albohy et al., 2013; Guo et al., 2018a; Guo et al., 2018b) We did not observe any significant effects for an inhibitor of NEU1 (IN1), which may indicate that the compound was not used at high enough dosage to counteract the most highlyexpressed NEU isoenzyme. We observed an increase in leukocyte counts from exudate after treatment of WT animals with an inhibitor of NEU4 (IN4); however, no significant differences from controls were observed from inhibitor treatment in animals after LPS stimulation. We noted that a selective inhibitor of NEU3 (IN3) reduced the difference in leukocyte counts between saline and LPS treatments (Figure 7A). We examined the effects of NEU inhibitors on leukocyte subsets (Figures SI5 \& SI6; Table SI6). Both IN3 and IN4 treatments resulted in 
increased MO cell counts for saline treatment relative to control. Furthermore, IN3 treatment gave a significant reduction in MФ counts after LPS treatment. We note that these experiments were at a single dosage and included a limited number of animals. As a result, follow up studies will be required to determine the potential of selective NEU inhibitors for affecting leukocyte infiltration.
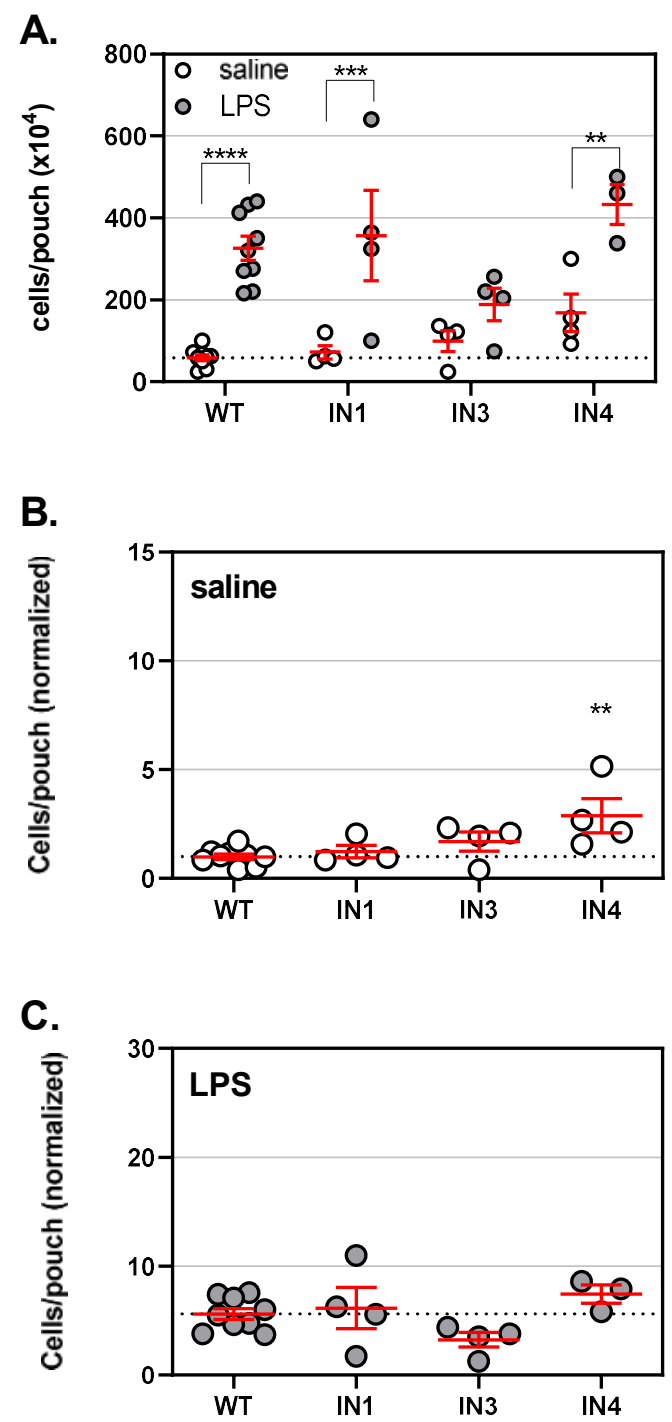

Figure 7. Leukocyte counts in the air pouch model are modulated by NEU inhibitors. An air pouch was formed in WT mice injected with inhibitor compounds or vehicle, followed by injection with saline or LPS to the air pouch and incubation for $9 \mathrm{~h}$. Inhibitors that target NEU1 (IN1, CG14600), NEU3 (IN3, CG22600), and NEU4 (IN4, CY16600) were used. Mice were then sacrificed, the pouch exudate was collected, and cells were counted by flow cytometry. A. Total cell counts are presented for saline $(O)$ and LPS $(\bullet)$ treatments. B. Cell counts for the saline treatment in the Neu KO mice are compared with those of WT mice. C. Cell counts for the LPS treatment are compared with those of WT mice. Data are presented as individual values and mean \pm SEM. For panel A, comparisons were made using two-way ANOVA following Bonferroni multiple comparison t-test; for panel B \& C, comparisons were made using one-way ANOVA with Dunnett's t-test for multiple comparison (*, 
$\mathrm{p} \leq 0.05 ; * *, \mathrm{p} \leq 0.01 ; * * *, \mathrm{p} \leq 0.005 ; * * * *, \mathrm{p} \leq 0.0001)$. Raw cell counts for leukocyte subsets are shown in

\section{Figure SI5.}

\section{Discussion}

Using an air-pouch model of inflammation in gene-targeted mouse strains and a panel of specific neuraminidase inhibitors, we have investigated the involvement of endogenous neuraminidase enzymes in the migration and recruitment of leukocytes to the site of LPS-induced acute inflammation.(Muller, 2013) Our data show that NEU1 and NEU3 act as positive regulators of the recruitment of leukocytes to the site of inflammation. In contrast, NEU4 acts as a negative regulator of leukocyte recruitment. These results were confirmed by immunohistochemistry of dermal and muscular layers of the air pouch walls. Furthermore, LPS-treated Neul KO, but not Neu4 KO, animals have significantly reduced levels of proinflammatory cytokines IL-1 $\beta$, MIP1- $\alpha$, MIP2, and TNF- $\alpha$ in air poach exudates. Thus, it can be concluded that NEU1 and NEU3, in general, exert proinflammatory effects, whereas NEU4 exerts anti-inflammatory effects.

Our data also demonstrated an increased basal level of inflammation in the control (saline treated) Neul KO mice including higher levels of MO and NE in the air pouch washes, increased leukocyte infiltration in dermis layers of the pouch walls, and higher concentrations of circulating TNF- $\alpha$, a pro-inflammatory cytokine. When interpreting these data, it is important to consider that complete deficiency of NEU1 results in a catabolic block in degradation of sialylated glycoproteins resulting in their lysosomal storage and leading to systemic metabolic disease, sialidosis.(Pshezhetsky \& Ashmarina, 2001) Previous studies in human patients and mouse models of sialidosis have revealed that progressive neuroinflammation and leukocyte infiltration in peripheral tissues are the hallmarks of this disease.(Wu et al, 2010) Signs of neuroinflammation including microastrogliosis and increased brain levels of MIP-1 $\alpha$ (CCL3) have been also reported for Neu3 KO, Neu4 KO, and Neu3/Neu4 DKO mice but the levels were substantially lower as compared to Neul KO animals.(Kho et al, 2020; Pan et al., 2017)

Because the results obtained in KO mice suggested that pharmacological inhibition of NEU1 and NEU3 could be used for manipulating the inflammatory response, we further tested if specific inhibitors of neuraminidases were able to modulate leukocyte recruitment in the air pouch model. The results of our experiments with an inhibitor of NEU1 (IN1) were not conclusive due to the high variability between animals. However, treatment with an inhibitor of NEU3 (IN3) was consistent with the enzyme's positive regulation of cell infiltration. Treatment with an inhibitor of NEU4 (IN4) was consistent with negative regulation of leukocyte recruitment. The inhibitors showed differential effects on leukocyte subsets, which may explain the divergence of these results from the gene-targeted animals. We observed that IN3 reduced leukocyte recruitment in response to LPS in mice in similar fashion to the genetic inactivation of the Neu3 gene. In contrast IN4 increased leukocyte recruitment under basal conditions. Interestingly, both the NEU3 and NEU4 inhibitors increased basal levels of MO and NE in the pouch (saline treatment). While these data are generally supportive of our conclusion that NEU4 is a 
negative regulator while NEU1 and NEU3 are positive regulators of inflammation, the specific effects are different from those obtained by gene-targeting. It is important to also note that only a single dose and regimen for inhibitor administration were tested and the cohort size was limited. As a result, we cannot exclude that pharmacokinetics, bioavailability, or membrane permeability of the compounds may influence these conclusions. Further studies exploring different doses of inhibitors will be needed to clarify these effects.

A potential mechanism for regulation of leukocyte recruitment to the site of inflammation by NEU enzymes is modulation of pro-inflammatory cytokines and chemokine production. Indeed, our results indicate that NEU1 activity positively regulates cytokines directly implicated in the recruitment of leukocytes to the site of inflammation such as IL-1 $\beta$, MIP-1 $\alpha$, and MIP-2.(Diab et al, 1999; Lotfi et al, 2019; Sherry et al, 1998) NEU1 overexpressing MФ are known to have increased expression of IL-1 $\beta$ and TNF- $\alpha$, consistent with our observation of these cytokines being attenuated in the Neul KO model.(Sieve et al, 2018) Previous studies have shown that treatment of cells with exogenous bacterial neuraminidases exert differential effects on cytokines and chemokines. For example, Stamatos and coworkers showed that exogenous treatment of purified human MO with neuraminidase from Clostridium perfringens increased production of IL-6, MIP-1 $\alpha$ (CCL3) and MIP-1 $\beta$ (CCL4), but had no effect on RANTES (CCL5), IL-10, TNF- $\alpha$, IFN- $\gamma$, and IL-1 $\beta$.(Stamatos et al, 2004) The differences in the results on the production of different cytokines and chemokines between this and our study could be due to different experimental approaches and enzyme specificities.

Neu4 $\mathrm{KO}$ mice, in contrast to Neul KO mice, had fewer changes to cytokine profiles. Our data regarding cell migration to the air pouch indicated elevated accumulation of MO, NE, and NK cells in the Neu4 KO model. This observation may be partly explained by elevated cytokine levels observed in exudate samples from these animals. We observed activation of 7 cytokines from $\mathrm{Neu} 4 \mathrm{KO}$ exudate samples. Among these are cytokines that are known to act as chemoattractants for leukocytes including MO, NE, or NK cells.(Choi et al, 2009; Diab et al., 1999; Gomez-Cambronero et al, 2003; Lotfi et al., 2019; Pelletier et al, 2004; Sherry et al., 1998) Together, these data suggest that NEU4 and NEU1 modulate cytokine levels which may explain the changes in leukocyte migration observed in these models. Further experiments will be required to test if cytokine levels are directly or indirectly affected by NEU deficiencies; however, our current data provide evidence for clear differences between WT, Neul KO and Neu4 KO mice cytokine levels and warrant future investigation.

We have demonstrated earlier that levels of NEU1 are increased at least 10-fold during the differentiation of MO to MФ, and that the enzyme is targeted from lysosomes to the cell membrane.(Liang et al, 2006; Stamatos et $a l, 2005)$ Furthermore, increased sialylation of cell surface receptors targeted by NEU1, including Fc- $\gamma$ receptors on $\mathrm{M} \Phi$, have been demonstrated in Cath $A^{\text {S190Aneo }}$ mice with $\sim 90 \%$ reduction of NEU1 activity. (Pshezhetsky \& Hinek, 2011; Seyrantepe et al., 2010) The Neul KO mouse is completely deficient in NEU1 and is likely to show enhanced sialylation of NEU1-targeted glycoconjugates including receptors and proteins involved in signalling cascades activated by LPS. In our study, we used LPS, a major component of the cell wall of Gram-negative 
bacteria, to induce inflammation in the air pouch. The binding of LPS to TLR-4 via CD14 (a GPI-anchored homodimer) induces TLR-4 dimerization and activates a signalling cascade that culminates in the activation of NF-kB, and production of pro-inflammatory cytokines and chemokines.(Kawasaki \& Kawai, 2014) We have reported that the TLR-4-induced signaling causes activation and translocation of endogenous NEU1 to the cell surface. The activated NEU1 desialylates TLR-4, and this process plays a critical role in the TLR-4-mediated activation of NF-kB.(Amith et al., 2010; Pshezhetsky \& Ashmarina, 2013) This mechanism may explain the reduced production of pro-inflammatory cytokines and chemokines in the Neul KO mouse. Not surprisingly, neuraminidase potentiates LPS-induced acute lung injury in mice.(Feng et al, 2013) Neul KO has been found to block LPS induction of TNF- $\alpha$ and IL-1 $\beta$ in monocytes.(Sieve et al., 2018) Besides potentiating TLR-4 signalling, cell surface protein hypersialylation may affect production of cytokines and chemokines by other mechanisms such as masking of galectin receptors or engagement of inhibitory Siglecs by trans- and cis-acting sialylated epitopes.(Pearce \& Läubli, 2016; Schauer, 2009) Further studies are required to clarify specific links between NEU1 and inflammasome activation.

The rolling and tethering of leukocytes onto endothelial cells is a first step in the extravasation of leukocytes to the sites of inflammation in the body.(Muller, 2013) The sialylated epitopes sLe ${ }^{\mathrm{a}}$ and $\mathrm{sLe}^{\mathrm{x}}(\mathrm{CD} 15 \mathrm{~s})$ are present on a variety of glycoproteins, such as PSGL-1 and CD44, and are critical for extravasation of normal leukocytes. These sialylated epitopes are also abundantly expressed on cancer cells and mediate their interaction through selectins on endothelial cells. Interestingly, Neu4S, the short cytoplasmic NEU4 isoform expressed in peripheral tissues, is downregulated in cancer and can desialylate these binding epitopes.(Shiozaki et al, 2011) This may suggest a molecular mechanism by which NEU4 could act as a negative regulator of leukocyte recruitment to a site of inflammation.

Our study revealed a positive role for NEU3 in the recruitment of leukocytes. Previous studies have found that neuraminidases can affect leukocyte recruitment by modulating activities of adhesion molecules.(Wright \& Cooper, 2014) Our previous work has suggested that NEU3 mediates desialylation of gangliosides and glycoproteins which may inhibit cis-interactions with $\beta 1$ integrins ( $\alpha 4 \beta 1$ and $\alpha 5 \beta 1$; also known as VLA4 and VLA5, respectively).(Howlader et al., 2019; Jia et al, 2016) Here, we confirmed that BMDM from Neu3 KO animals had increased in vitro chemotaxis through a FN-coated membrane, consistent with this isoenzyme acting as a negative regulator of cell migration in response to a chemoattractant (MCP-1/CCL2). In contrast, Neu1 KO animals showed reduced migration in vitro. Further studies are required to clarify the mechanism by which NEU1 induces leukocyte transmigration, but it is notable that the $\mathrm{MCP}-1$ receptor, $\mathrm{CCR} 2$, is sialylated.(Matsubara et al, 2015) BMDM from Neu4 KO mice did not show differences from control in the migration assay, which may indicate that the enzyme regulates a different aspect of leukocyte recruitment. We hope that our findings will spur future investigations of leukocyte activation to explore the specific mechanisms responsible for these effects more fully. 
In conclusion, this study has demonstrated that neuraminidase isoenzymes play a key role in LPS-stimulated acute inflammatory response. These effects were highly dependent upon the NEU isoenzyme tested. We found that NEU1 and NEU3 activity was pro-inflammatory, while NEU4 activity was anti-inflammatory. Together, these results bolster the case for differential involvement of NEU isoenzymes in the activation and infiltration of leukocytes during inflammation. This discovery could provide new targets for therapeutics and may indicate an unrecognized role for NEU in immune cell regulation. Further work is necessary to determine the specific mechanisms regulated by each enzyme tested here.

\section{Supporting information}

Additional Supporting information can be found online in the Supporting Information section.

\section{Acknowledgements}

We are grateful for the use of facilities provided by the University of Alberta Department of Chemistry. IHC was performed by Sullen Lamb, Histology Lab Services, University of Alberta.

\section{Funding information}

This work was supported by a GlycoNet student travel grant (MAH), GlycoNet collaborative team grants (CD2: CWC \& AVP; ID-01: CWC, AVP, AA), and the Canadian Institutes of Health Research (Grant PJT-148863, CWC \& AVP).

\section{Conflict of interest}

MAH, CWC, TG, AVP are inventors on patent applications related to this work.

\section{Author contributions}

MAH, ED, SS, AA, AVP, and CWC designed research; MAH, ED, and SS performed research and analyzed data; TG contributed new reagents; MAH, AA, AVP, and CWC wrote the manuscript. 
bioRxiv preprint doi: https://doi.org/10.1101/2021.07.14.452400; this version posted July 14, 2021. The copyright holder for this preprint (which was not certified by peer review) is the author/funder, who has granted bioRxiv a license to display the preprint in perpetuity. It is made available under aCC-BY-NC-ND 4.0 International license.

\section{ORCID}

Md. Amran Howlader, https://orcid.org/0000-0002-1872-3480

Ekaterina P. Demina, https://orcid.org/0000-0002-0152-6122

Suzanne Samarani, https://orcid.org/0000-0003-3601-401X

Tianlin Guo, https://orcid.org/0000-0001-5096-2070

Ali Ahmad, https://orcid.org/0000-0001-7689-7115

Alexey V. Pshezhetsky, https://orcid.org/0000-0002-6612-1062

Christopher W Cairo, https://orcid.org/0000-0003-3363-8708 
bioRxiv preprint doi: https://doi.org/10.1101/2021.07.14.452400; this version posted July 14,2021 . The copyright holder for this preprint (which was not certified by peer review) is the author/funder, who has granted bioRxiv a license to display the preprint in perpetuity. It is made available under aCC-BY-NC-ND 4.0 International license.

\section{Tables}

Table 1. Leukocyte raw cell counts observed in the air pouch model.

\begin{tabular}{|c|c|c|c|c|c|c|}
\hline & \multicolumn{3}{|l|}{$\begin{array}{l}\text { Saline } \\
\left(\text { cells } \times 10^{4}\right)\end{array}$} & \multicolumn{3}{|l|}{$\begin{array}{l}\text { LPS } \\
\left(\text { cells } \times 10^{4}\right)\end{array}$} \\
\hline & Mean \pm SEM & $p$ & $\mathrm{~N}$ & Mean \pm SEM & $p$ & $\mathrm{~N}$ \\
\hline WT C57BL6 & $58 \pm 8$ & & 9 & $326 \pm 29$ & & 9 \\
\hline Neu1 KO & $111 \pm 34$ & & 4 & $79 \pm 9$ & $\star \star \star \star$ & 5 \\
\hline Neu3 KO & $59 \pm 12$ & & 4 & $259 \pm 54$ & & 4 \\
\hline Neu4 KO & $83 \pm 9$ & & 4 & $1371 \pm 229$ & $\star \star \star$ & 4 \\
\hline Neu3/4 DKO & $54 \pm 12$ & & 4 & $992 \pm 141$ & $\star \star \star \star$ & 4 \\
\hline WT IN1 & $72 \pm 16$ & & 4 & $357 \pm 111$ & & 4 \\
\hline WT IN3 & $100 \pm 26$ & & 4 & $189 \pm 40$ & & 4 \\
\hline WT IN4 & $172 \pm 43$ & $\star \star$ & 4 & $433 \pm 49$ & & 3 \\
\hline
\end{tabular}

Values were compared to control using a Student's t-test (*, $\mathrm{p} \leq 0.05 ; * *, \mathrm{p} \leq 0.01 ; * * *, \mathrm{p} \leq 0.005 ; * * * *, \mathrm{p} \leq$ $0.0001)$. 
Table 2: Summary of changes to cytokine levels in Neu1 and Neu4 KO animals.

\begin{tabular}{|c|c|c|c|c|}
\hline Model & & Basal activated $\dagger$ & Activated $\$$ & Attenuated§ \\
\hline \multirow[t]{2}{*}{ Neu1 KO } & exudate & IL-10, IL-33 & G-CSF & $\begin{array}{c}\text { G-CSF, } \\
\text { IL-1 } \beta, \text { IL-6, IL-10, } \\
\text { MIP-1 } \alpha, \text { MIP-2, } \\
\text { TNF- } \alpha\end{array}$ \\
\hline & plasma & $\begin{array}{l}\text { IL-1 } \alpha, \text { IL-1 } \beta \text {, } \\
\text { IL-15, IL-25, } \\
\text { MIP-2 }\end{array}$ & TNF- $\alpha$ & $\begin{array}{c}\text { G-CSF, RANTES, } \\
\text { IL-6, IL-10, } \\
\text { IFN- } \gamma, \text { MIP-1 } \alpha, \text { MIP-1 } \beta, \text { MIP-2 }\end{array}$ \\
\hline \multirow[t]{2}{*}{ Neu4 KO } & exudate & & $\begin{array}{c}\text { GM-CSF, } \\
\text { IL-1 } \beta, \\
\text { IL-21, IL-33, } \\
\text { MIP-1 } \alpha, \text { MIP-1 } \beta, \text { MIP-2 }\end{array}$ & $\begin{array}{l}\text { G-CSF, } \\
\text { IFN- } \gamma \\
\text { MCP-1 }\end{array}$ \\
\hline & plasma & IP-10 & & $\begin{array}{l}\text { G-CSF, RANTES, } \\
\text { IL-10, } \\
\text { MIP-1 } \alpha, \text { MIP-1 } \beta\end{array}$ \\
\hline
\end{tabular}

$\dagger$, Basal activated was defined as having a significant increase in saline for the model relative to saline control. † Activated was defined as having a significant positive difference between control LPS and model LPS stimulation.

$\S$, Attenuated was defined as having a significant negative difference between control LPS and model LPS stimulation. 
bioRxiv preprint doi: https://doi.org/10.1101/2021.07.14.452400; this version posted July 14, 2021. The copyright holder for this preprint (which

was not certified by peer review) is the author/funder, who has granted bioRxiv a license to display the preprint in perpetuity. It is made available under aCC-BY-NC-ND 4.0 International license.

Table 3: hNEU inhibitors used in this study.

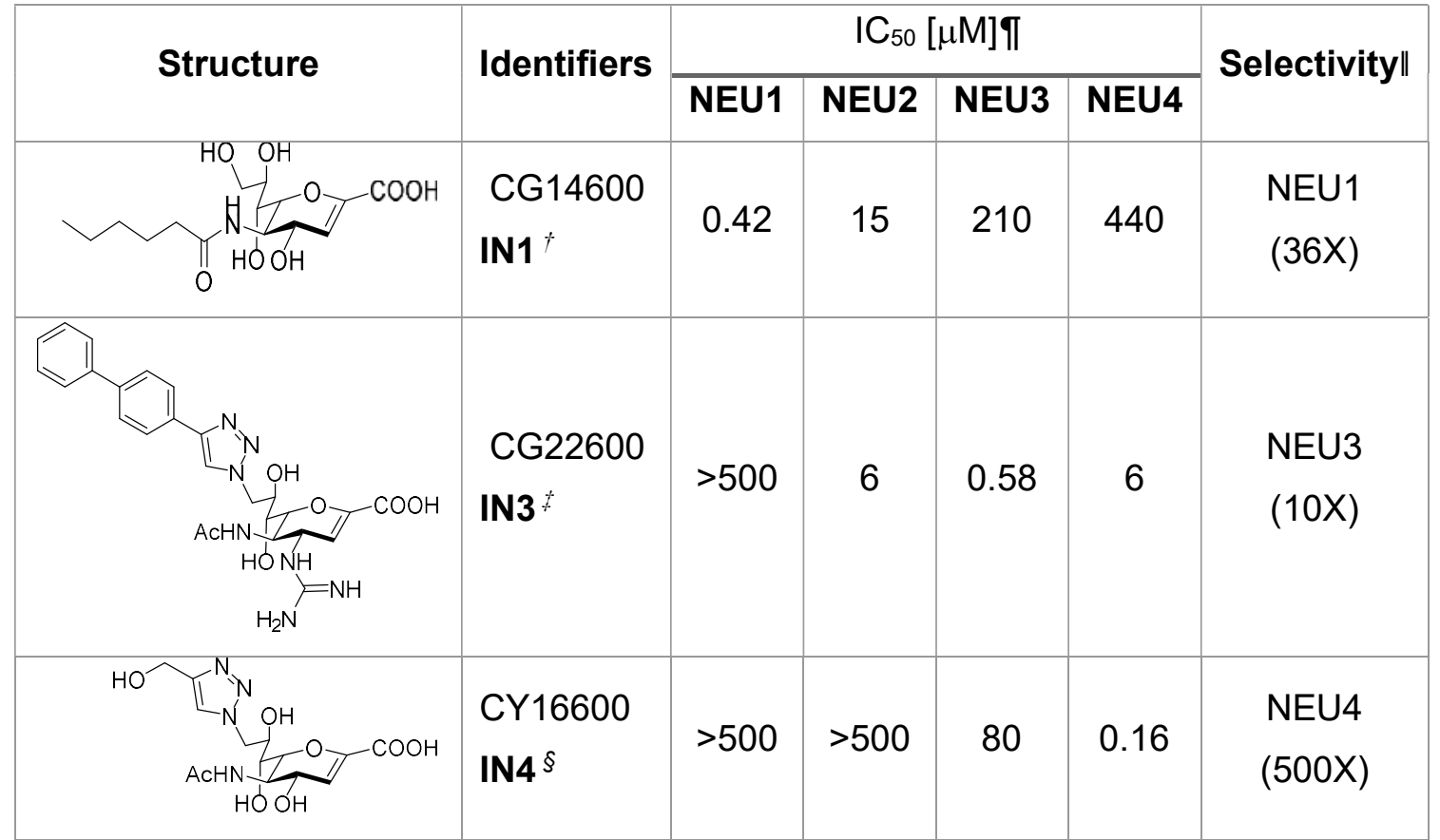

$\dagger$, Referred to as compound 11d in original citation.(Guo et al., 2018b)

f. Referred to as compound $\mathbf{8 b}$ in original citation.(Guo et al., 2018a)

$\S$, Referred to as compound 6 in original citation;(Albohy et al., 2013) or C9-(4-hydroxymethyltriazolyl)-DANA (C94HMT-DANA); referred to here as CY16600.

I, $\mathrm{IC}_{50}$ values from previous studies against a 4MU-NANA substrate are provided with the indicated citation.

$\|$, Selectivity based on $\mathrm{IC}_{50}$ values cited (and may be an upper limit), with fold-selectivity between the best and next-best target shown in parenthesis. 


\section{References}

Albohy A, Zhang Y, Smutova V, Pshezhetsky AV, Cairo CW (2013) Identification of Selective Nanomolar Inhibitors of the Human Neuraminidase, NEU4. ACS Med Chem Lett 4: 532-537

Amith SR, Jayanth P, Franchuk S, Finlay T, Seyrantepe V, Beyaert R, Pshezhetsky AV, Szewczuk MR (2010) Neul desialylation of sialyl $\alpha$-2,3-linked $\beta$-galactosyl residues of TOLL-like receptor 4 is essential for receptor activation and cellular signaling. Cell Signal 22: 314-324

Choi Y-S, Choi H-J, Min J-K, Pyun B-J, Maeng Y-S, Park H, Kim J, Kim Y-M, Kwon Y-G (2009) Interleukin33 induces angiogenesis and vascular permeability through ST2/TRAF6-mediated endothelial nitric oxide production. Blood, The Journal of the American Society of Hematology 114: 3117-3126

Cronstein BN, Naime D, Ostad E (1993) The antiinflammatory mechanism of methotrexate. Increased adenosine release at inflamed sites diminishes leukocyte accumulation in an in vivo model of inflammation. The Journal of clinical investigation 92: 2675-2682

Cross AS, Sakarya S, Rifat S, Held TK, Drysdale B-E, Grange PA, Cassels FJ, Wang L-X, Stamatos N, Farese A et al (2003) Recruitment of Murine Neutrophils in Vivothrough Endogenous Sialidase Activity. Journal of Biological Chemistry 278: 4112-4120

Diab A, Abdalla H, Li HL, Shi FD, Zhu J, Höjberg B, Lindquist L, Wretlind B, Bakhiet M, Link H (1999) Neutralization of macrophage inflammatory protein 2 (MIP-2) and MIP-1 $\alpha$ attenuates neutrophil recruitment in the central nervous system during experimental bacterial meningitis. Infect Immun 67: 2590-2601

Feng C, Zhang L, Almulki L, Faez S, Whitford M, Hafezi-Moghadam A, Cross AS (2011) Endogenous PMN sialidase activity exposes activation epitope on CD11b/CD18 which enhances its binding interaction with ICAM1. J Leukocyte Biol 90: 313-321

Feng C, Zhang L, Nguyen C, Vogel SN, Goldblum SE, Blackwelder WC, Cross AS (2013) Neuraminidase Reprograms Lung Tissue and Potentiates Lipopolysaccharide-Induced Acute Lung Injury in Mice. The Journal of Immunology 191: 4828-4837

Feng CG, Stamatos NM, Dragan AI, Medvedev A, Whitford M, Zhang L, Song C, Rallabhandi P, Cole L, Nhu QM et al (2012) Sialyl Residues Modulate LPS-Mediated Signaling through the Toll-Like Receptor 4 Complex. Plos One 7

Gadhoum SZ, Sackstein R (2008) CD15 expression in human myeloid cell differentiation is regulated by sialidase activity. Nat Chem Biol 4: 751-757

Gomez-Cambronero J, Horn J, Paul CC, Baumann MA (2003) Granulocyte-macrophage colony-stimulating factor is a chemoattractant cytokine for human neutrophils: involvement of the ribosomal p70 S6 kinase signaling pathway. The Journal of Immunology 171: 6846-6855

Guo T, Datwyler P, Demina E, Richards MR, Ge P, Zou C, Zheng R, Fougerat A, Pshezhetsky AV, Ernst B et al (2018a) Selective Inhibitors of Human Neuraminidase 3. J Med Chem 61: 1990-2008

Guo T, Heon-Roberts R, Zou C, Zheng R, Pshezhetsky AV, Cairo CW (2018b) Selective Inhibitors of Human Neuraminidase 1 (NEU1). J Med Chem 61: 11261-11279 
Howlader MA, Li C, Zou C, Chakraberty R, Ebesoh N, Cairo CW (2019) NEU3 is a negative regulator of LFA1 adhesion. Frontiers in Chemistry 7: 791

Jia F, Howlader MA, Cairo CW (2016) Integrin-mediated cell migration is blocked by inhibitors of human neuraminidase. Biochimica et Biophysica Acta (BBA) - Molecular and Cell Biology of Lipids 1861: 1170-1179

Kawasaki T, Kawai T (2014) Toll-like receptor signaling pathways. Frontiers in immunology 5: 461

Kho I, Pan X, Cairo C, Morales CM, Pshezhetsky A (2020) Study of a novel neuraminidase 1 knockout mouse links the pathology of sialidosis in the nervous, renal and reproductive system. Mol Genet Metab 129: S88

Ley K, Laudanna C, Cybulsky MI, Nourshargh S (2007) Getting to the site of inflammation: the leukocyte adhesion cascade updated. Nat Rev Immunol 7: 678-689

Liang F, Seyrantepe V, Landry K, Ahmad R, Ahmad A, Stamatos NM, Pshezhetsky AV (2006) Monocyte Differentiation Up-regulates the Expression of the Lysosomal Sialidase, Neu1, and Triggers Its Targeting to the Plasma Membrane via Major Histocompatibility Complex Class II-positive Compartments. J Biol Chem 281: 27526-27538

Lindberg B, Lindh F, Lönngren J, Lindberg AA, Svenson SB (1981) Structural studies of the O-specific sidechain of the lipopolysaccharide from Escherichia coli O 55. Carbohydr Res 97: 105-112

Lotfi N, Thome R, Rezaei N, Zhang G-X, Rezaei A, Rostami A, Esmaeil N (2019) Roles of GM-CSF in the pathogenesis of autoimmune diseases: an update. Frontiers in immunology 10: 1265

Matsubara K, Matsushita Y, Sakai K, Kano F, Kondo M, Noda M, Hashimoto N, Imagama S, Ishiguro N, Suzumura A (2015) Secreted ectodomain of sialic acid-binding Ig-like lectin-9 and monocyte chemoattractant protein-1 promote recovery after rat spinal cord injury by altering macrophage polarity. J Neurosci 35: 2452-2464

Miyagi T, Yamaguchi K (2012) Mammalian sialidases: Physiological and pathological roles in cellular functions. Glycobiology 22: 880-896

Miyake K (2004) Innate recognition of lipopolysaccharide by Toll-like receptor 4-MD-2. Trends Microbiol 12: $186-192$

Muller WA (2013) Getting leukocytes to the site of inflammation. Veterinary pathology 50: 7-22

Nan X, Carubelli I, Stamatos NM (2007) Sialidase expression in activated human T lymphocytes influences production of IFN-gamma. J Leukoc Biol 81: 284-296

Nguyen KD, Fentress SJ, Qiu Y, Yun K, Cox JS, Chawla A (2013) Circadian Gene Bmall Regulates Diurnal Oscillations of Ly6C ${ }^{\text {hi }}$ Inflammatory Monocytes. Science 341: 1483-1488

Pan X, De Aragao CBP, Velasco-Martin JP, Priestman DA, Wu HY, Takahashi K, Yamaguchi K, Sturiale L, Garozzo D, Platt FM et al (2017) Neuraminidases 3 and 4 regulate neuronal function by catabolizing brain gangliosides. FASEB J 31: 3467-3483

Pearce OMT, Läubli H (2016) Sialic acids in cancer biology and immunity. Glycobiology 26: 111-128

Pelletier M, Bouchard A, Girard D (2004) In vivo and in vitro roles of IL-21 in inflammation. The Journal of Immunology 173: 7521-7530 
Pshezhetsky AV, Ashmarina LI (2013) Desialylation of surface receptors as a new dimension in cell signaling. Biochemistry (Moscow) 78: 736-745

Pshezhetsky AV, Ashmarina M (2001) Lysosomal multienzyme complex: biochemistry, genetics, and molecular pathophysiology. Prog Nucleic Acid Res Mol Biol 69: 81-114

Pshezhetsky AV, Hinek A (2011) Where catabolism meets signalling: neuraminidase 1 as a modulator of cell receptors. Glycoconjugate J 28: 441-452

Quinn MT, Swain SD, Parkos CA, Jutila KL, Siemsen DW, Kurk SL, Jesaitis AJ, Jutila MA (2001) A carbohydrate neoepitope that is up-regulated on human mononuclear leucocytes by neuraminidase treatment or by cellular activation. Immunology 104: 185-197

Rossol M, Heine H, Meusch U, Quandt D, Klein C, Sweet MJ, Hauschildt S (2011) LPS-induced Cytokine Production in Human Monocytes and Macrophages. 31: 379-446

Sakarya S, Rifat S, Zhou J, Bannerman DD, Stamatos NM, Cross AS, Goldblum SE (2004) Mobilization of neutrophil sialidase activity desialylates the pulmonary vascular endothelial surface and increases resting neutrophil adhesion to and migration across the endothelium. Glycobiology 14: 481-494

Schauer R (2009) Sialic acids as regulators of molecular and cellular interactions. Curr Opin Struct Biol 19: 507514

Senger DR, Perruzzi CA, Streit M, Koteliansky VE, de Fougerolles AR, Detmar M (2002) The $\alpha 1 \beta 1$ and $\alpha 2 \beta 1$ Integrins Provide Critical Support for Vascular Endothelial Growth Factor Signaling, Endothelial Cell Migration, and Tumor Angiogenesis. The American Journal of Pathology 160: 195-204

Seyrantepe V, Iannello A, Liang F, Kanshin E, Jayanth P, Samarani S, Szewczuk MR, Ahmad A, Pshezhetsky AV (2010) Regulation of Phagocytosis in Macrophages by Neuraminidase 1. The Journal of Biological Chemistry 285: $206-215$

Sherry B, Espinoza M, Manogue KR, Cerami A (1998) Induction of the Chemokine $\beta$ Peptides, MIP-1 $\alpha$ and MIP-1 $\beta$, by Lipopolysaccharide Is Differentially Regulated by Immunomodulatory Cytokines $\gamma$-IFN, IL-10, IL4, and TGF- $\beta$. Molecular medicine 4: 648-657

Shiozaki K, Yamaguchi K, Takahashi K, Moriya S, Miyagi T (2011) Regulation of Sialyl Lewis Antigen Expression in Colon Cancer Cells by Sialidase NEU4. J Biol Chem 286: 21052-21061

Sieve I, Ricke-Hoch M, Kasten M, Battmer K, Stapel B, Falk CS, Leisegang MS, Haverich A, Scherr M, HilfikerKleiner D (2018) A positive feedback loop between IL-1 $\beta$, LPS and NEU1 may promote atherosclerosis by enhancing a pro-inflammatory state in monocytes and macrophages. Vasc Pharmacol 103: 16-28

Sin YM, Sedgwick AD, Chea EP, Willoughby DA (1986) Mast cells in newly formed lining tissue during acute inflammation: a six day air pouch model in the mouse. Annals of the Rheumatic Diseases 45: 873-877

Smutova V, Albohy A, Pan X, Korchagina E, Miyagi T, Bovin N, Cairo CW, Pshezhetsky AV (2014) Structural Basis for Substrate Specificity of Mammalian Neuraminidases. PLoS One 9: e106320

Stamatos NM, Carubelli I, van de Vlekkert D, Bonten EJ, Papini N, Feng C, Venerando B, d'Azzo A, Cross AS, Wang LX et al (2010) LPS-induced cytokine production in human dendritic cells is regulated by sialidase activity. J Leukoc Biol 88: 1227-1239 
Stamatos NM, Curreli S, Zella D, Cross AS (2004) Desialylation of glycoconjugates on the surface of monocytes activates the extracellular signal-related kinases ERK $1 / 2$ and results in enhanced production of specific cytokines. J Leukocyte Biol 75: 307-313

Stamatos NM, Liang F, Nan X, Landry K, Cross AS, Wang LX, Pshezhetsky AV (2005) Differential expression of endogenous sialidases of human monocytes during cellular differentiation into macrophages. The FEBS journal 272: $2545-2556$

Terkeltaub R, Baird S, Sears P, Santiago R, Boisvert W (1998) The murine homolog of the interleukin-8 receptor CXCR-2 is essential for the occurrence of neutrophilic inflammation in the air pouch model of acute urate crystalinduced gouty synovitis. Arthritis Rheum 41: 900-909

Tessier PA, Naccache PH, Clark-Lewis I, Gladue RP, Neote KS, McColl SR (1997) Chemokine networks in vivo: involvement of C-X-C and C-C chemokines in neutrophil extravasation in vivo in response to TNF-alpha. The Journal of Immunology 159: 3595-3602

Wright RD, Cooper D (2014) Glycobiology of leukocyte trafficking in inflammation. Glycobiology 24: 12421251

Wu X, Steigelman KA, Bonten E, Hu H, He W, Ren T, Zuo J, d'Azzo A (2010) Vacuolization and alterations of lysosomal membrane proteins in cochlear marginal cells contribute to hearing loss in neuraminidase 1-deficient mice. Biochimica et Biophysica Acta (BBA)-Molecular Basis of Disease 1802: 259-268

Zen K, Cui L-B, Zhang C-Y, Liu Y (2007) Critical Role of Mac-1 Sialyl Lewis X Moieties in Regulating Neutrophil Degranulation and Transmigration. J Mol Biol 374: 54-63

Zhang Y, Albohy A, Zou Y, Smutova V, Pshezhetsky AV, Cairo CW (2013) Identification of Selective Inhibitors for Human Neuraminidase Isoenzymes Using C4,C7-Modified 2-Deoxy-2,3-didehydro-N-acetylneuraminic Acid (DANA) Analogues. Journal of Medicinal Chemistry 56: 2948-2958 